\title{
Inteligência competitiva e Internet: um processo otimizado por agentes inteligentes - um estudo parcial de caso
}

\author{
Competitive intelligence and Internet: a process optimized \\ by intelligent agents - a partial study of case
}

Adriana Duarte NADAES ${ }^{1}$

Mônica Erichsen Nassif BORGES'

\section{R E S U M O}

\section{A B S T R A C T}

Este artigo apresenta a proposta de uma atividade de Inteligência Competitiva (IC) através da Internet, com o objetivo de possibilitar a utilização de agentes inteligentes na tarefa de monitoramento de fontes de informação disponíveis na rede. O presente trabalho foi desenvolvido até o ponto relativo ao mapeamento de fontes de informação estratégicas disponíveis na Internet, imaginando-se a possibilidade de sua aplicação em qualquer organização. O referencial empírico do trabalho foi em uma empresa mineira do setor de consultoria e prestação de serviços em gestão da informação e documentação.

Palavras-chave: inteligência competitiva, estratégia organizacional, pequenas e médias empresas, Internet, agentes inteligentes.

This is a proposal for a competitive intelligence activity through the Internet, in order to make possible the use of intelligent agents in the monitoring of information sources available in the network. The present project has already been developed up to the mapping of sources of strategic information found in the Internet, working with the possibility of applying it to any organization. The project's empirical

\footnotetext{
1 Docentes, Escola de Ciência da Informação, Universidade Federal de Minas Gerais. Av. Antônio Carlos, 6627, 30161-970, Belo Horizonte, MG, Brasil. Correspondência para/Correspondence to: A.D. NADAES. E-mail: <adriananadaes@terra.com.br>. Recebido em 28/6/2004 e aceito para publicação em 16/2/2005.
} 
reference was an organization located in Minas Gerais (a State of Brazil), which works with consulting and services on documentation and. information management.

Key words: competitive intelligence, organizational strategy, small and medium-size enterprises (SME), Internet, intelligent agents.

\section{N T R O D U Ç Ã O}

O objetivo final do projeto é apresentar uma proposta de um processo de Inteligência Competitiva (IC), através da Internet, com possibilidade futura de utilização de agentes inteligentes na tarefa de monitoramento das fontes de informação disponíveis na rede e consideradas estratégicas por organizações de qualquer tipo ou porte. No presente estágio do trabalho, entretanto, priorizou-se o estudo das possibilidades de inserção de atividades de IC através da Internet em empresas de PME.

O trabalho utiliza a metodologia desenvolvida por Silva (2000), cujos aspectos básicos foram estudados em uma empresa mineira de consultoria em gestão da informação e documentação. A partir das definições ali encontradas, buscou-se responder às seguintes questões: Qual o valor das informações na tomada de decisão estratégica da empresa? Quais as fontes de informação utilizadas? Quais são as informações necessárias para os executivos de nível estratégico da empresa? Quais os recursos de monitoramento ambiental, agregação de valor e disseminação de informação que a alta administração possui para dar suporte à tomada de decisão estratégica?

As respostas a essas questões foram consideradas básicas para a estruturação de um processo de inteligência competitiva para a empresa, tendo-se a Internet como o principal recurso para que as informações estratégicas fossem monitoradas.

\section{Inteligência competitiva e a arquitetura de agentes inteligentes}

Tratar da informação implica na explicitação dos conceitos relacionadas a ela nos seus variados aspectos, o que não é fácil, pois os termos dado, informação, conhecimento e inteligência apresentam-se na literatura com as mais diversas concepções. Para cada um dos termos, encontramos várias definições, pois, quanto a esses conceitos, os autores são freqüentemente discordantes e conflitantes.

Independente da questão conceitual, gradativamente o aspecto mais importante tem passado a ser considerar o processo de gestão da informação como um processo estruturado de coleta, tratamento e contextualização de dados, transformando-os em bens aproveitáveis e pertinentes às necessidades estratégicas das organizações. Ao final, constata-se ser fundamental a disseminação adequada da informação, no sentido de garantir não só a sobrevivência da organização, mas a sua capacidade de reconhecer as próprias competências essenciais e de estabelecer com maior clareza suas definições estratégicas.

A inteligência competitiva (IC) tem-se tornado uma atividade imperativa para as organizações, devido àquelas questões e a fatores atuais tais como a velocidade dos processos de negócios, a sobrecarga de informações, o crescimento global do processo competitivo com o surgimento de novos participantes, a concorrência cada vez mais acirrada, as rápidas transformações tecnológicas e as mudanças acarretadas pela entrada em cena global de entidades como a União Européia (EU) e o Acordo de Livre Comércio da América do Norte (Nafta).

A inteligência competitiva pode ser vista como o processo de coleta e análise sistemática de informações que gera subsídios para a tomada de decisão organizacional. A habilidade com que 
a empresa coleta, organiza, analisa e implementa mudanças a partir de informações estratégicas, integrando-as ao processo de melhoria contínua de suas atividades, determinará a sua excelência frente ao ambiente de negócios.

Porter (1991), desde o início da década de 80 , chama a atenção para uma série de atividades que devem ser realizadas corretamente, para obter-se a vantagem competitiva a partir de uma estratégia competitiva global. Esta estratégia deve identificar as cinco forças competitivas presentes no ambiente organizacional externo: a entrada de novos concorrentes; a ameaça de substitutos; o poder de negociação dos compradores; o poder de negociação dos fornecedores e a rivalidade entre os concorrentes existentes. Porter (1991) coloca o foco da estratégia no ambiente externo.

A Figura 1, criada por Silva (2000, p.4) com base na visão de Tyson (1998), indica que inteligência competitiva é um processo de análise da informação do princípio ao fim; um processo que envolve coleta de informação sobre competidores, consumidores, fornecedores, possíveis concorrentes, possíveis associações e alianças estratégicas. Enfim, esses autores consideram que, toda e qualquer entidade e evento no meio ambiente externo da organização, vem vinculada à gestão estratégica e baseada no modelo das forças competitivas de Porter (1991), cujo foco no meio ambiente externo, considera ademais a interação das ameaças e das oportunidades externas à empresa, que afeta a sua estratégia e a sua habilidade para competir.

Portanto, a IC é uma atividade intensa, um ciclo de análises de informação para subsidiar a tomada de decisão, o que pode implicar na mudança total de estratégia, ou mesmo, na redefinição do negócio da organização.

No sentido de agilizar o processo de IC nas organizações Silva (2000, p.81), apresenta uma arquitetura de agentes inteligentes, cujas bases foram utilizadas neste trabalho.

A adoção dessa metodologia deve-se ao fato de que, neste trabalho defende-se a idéia de que muitas das informações disponíveis na Internet podem ser de grande relevância para as empresas. Para as PME, a obtenção de informa-

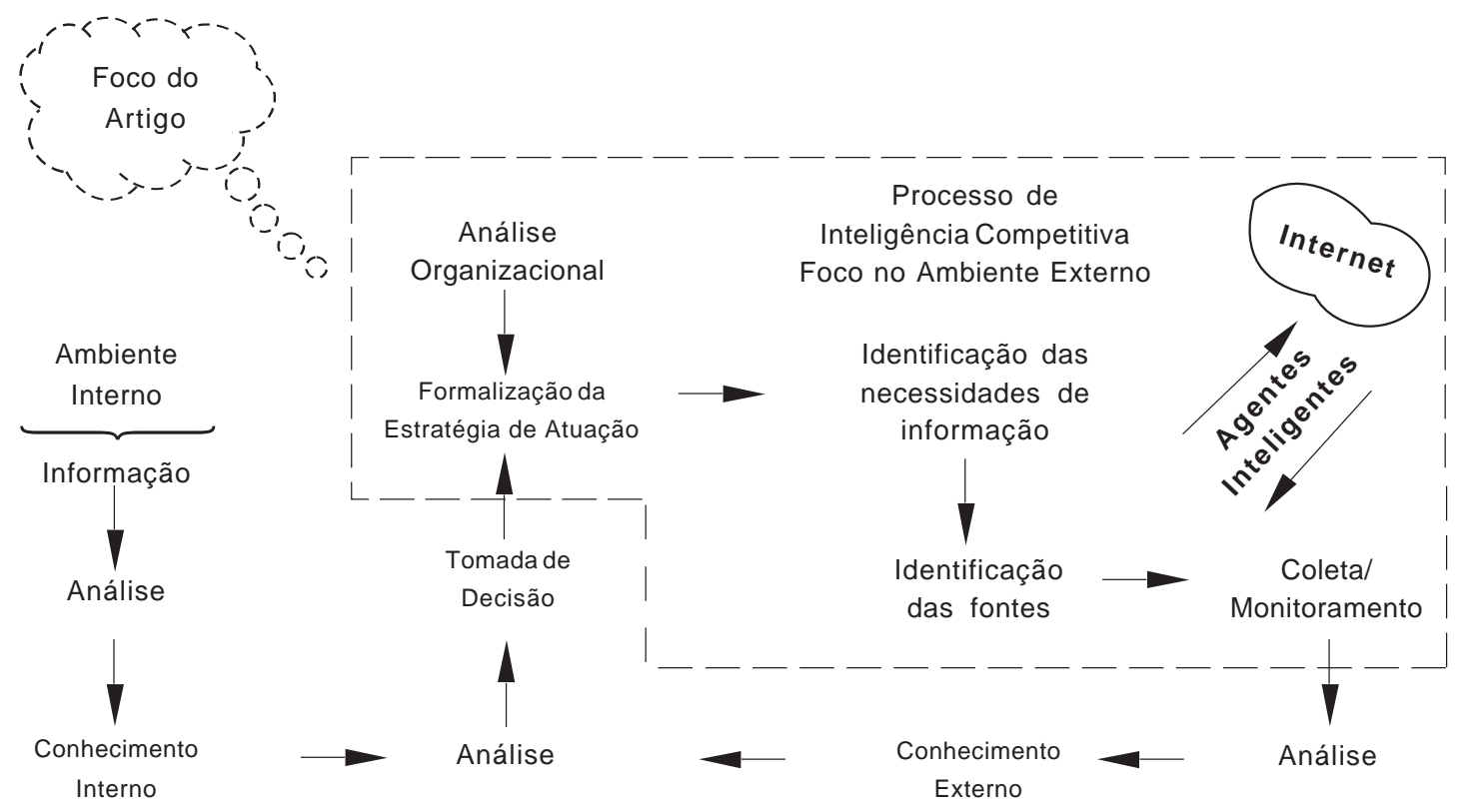

Figura 1. Processo de inteligência organizacional. 
ções estratégicas utilizando-se recursos da rede como fontes de informação, é uma possibilidade real e de baixo custo.

Silva (2000, p.106) propõe a criação de uma arquitetura onde os agentes são programados para estarem "atentos" às mudanças ocorridas nos sites determinados em uma base de endereços. A Figura 2, apresenta a arquitetura proposta para a atividade, onde são definidos quatro tipos de agentes: interface ${ }^{2}$, busca ${ }^{3}$, monitoramento ${ }^{4}$ e filtragem ${ }^{5}$. Esses agentes estão organizados de forma que possam ser acessados por meio de um sistema computacional ou por meio de um navegador Internet (diretamente pelo usuário). Em ambos os casos, o agente de interface exerce a tarefa de intermediar a interação.

\section{As pequenas e médias empresas}

É inegável que as PME têm uma importância vital para a economia de um país. No Brasil, podemos observar atualmente um forte interesse e tendência no sentido de conhecer, analisar e propor alternativas para o segmento empresarial formado pelas PME. Verifica-se a existência de programas de governos voltados para apoiar as empresas de pequeno porte.

A ênfase dada pelo governo às $P M E$ decorre da importância das mesmas para o país e das dificuldades por que passam para se manterem no mercado. Um estudo realizado em 2001, pelo Sistema de Apoio às Micro e Pequenas Empresas (Sebrae), demonstrou que o índice de mortalidade de empresas neste seguimento empresarial é muito elevado. Estima-

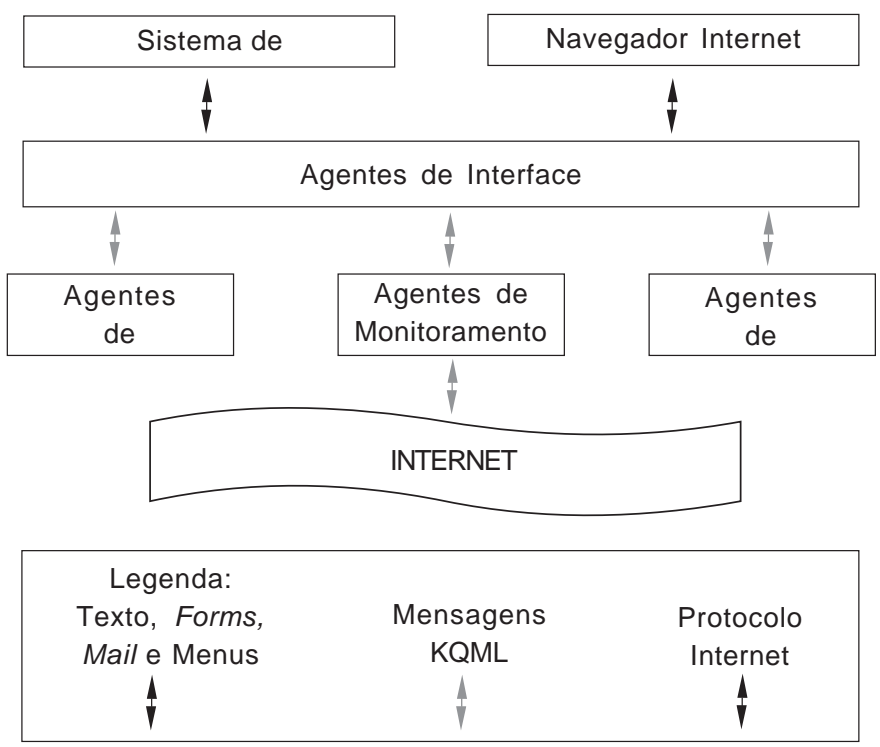

Figura 2. Arquitetura de Agentes para o Sistema de Recuperação de Informações. KQML (Knowledge and Query Manipulation) - Linguagem de comunicação entre agentes.

\footnotetext{
2 Agentes de Interface - são sistemas semi-inteligentes que ajudam o usuário em suas tarefas diárias, baseadas no computador.

3 Agentes de Busca - são aqueles capazes de buscar informações de forma inteligente. O objetivo desses agentes não é simplesmente encontrar informações que satisfaçam um conjunto de palavras-chave, mas que possam reconhecer padrões de informação e encontrar aquelas mais relevantes.

4 Agentes de Monitoramento - também definidos como notificadores, irão prover serviços de notificação que avisam aos agentes de interface sobre modificações no conteúdo de determinadas páginas. As páginas a serem monitoradas estão cadastradas em um banco de dados, o qual pode ser alimentado diretamente pelos usuários ou pelos agentes de interface.

${ }^{5}$ Agentes de Filtragem - são aqueles que oferecem atualização automática de notícias que se encaixam dentro dos interesses do serviço de informação ou biblioteca. Esses agentes trabalham em conjunto com os agentes de monitoramento.
} 
-se que cerca de $80 \%$ das PME desaparecem do mercado no primeiro ano de atividade e, até o final do quinto ano, $92 \%$ fecham as suas portas. Esse fato é causado pela escassa capacitação gerencial dos empreendedores, tendo como fatores críticos as faltas de: a) planejamento de produção e vendas, b) sistemas de apuração e controle, c) técnicas de marketing, d) treinamento de recursos humanos e, e) recursos de informática, entre outros.

As PME são fontes de empregos e são unidades geradoras de impostos com a capacidade de ampliar a oferta de produtos para o consumidor e estimular a concorrência de preços e qualidade. O contraponto de tudo isto é a constatação de que, no Brasil, os estudos dedicados a compreender o fenômeno de criação deste segmento empresarial são muito incipientes, questão esta que se tornou evidente na realização deste trabalho.

No Livro Verde da Sociedade da Informação no Brasil (2000), as PME são reconhecidas pela sua importância econômica para o país, e é salientada a necessidade de se criar mecanismos para que essas empresas possam ter acesso à Internet e, conseqüentemente, ao comércio eletrônico, para ampliação de suas oportunidades de negócios. O documento mostra que a dificuldade das PME em obterem aporte de tecnologias de informação não está na área técnica, mas na financeira.

As PME necessitam também desenvolver uma cultura voltada para o gerenciamento da informação e, de forma simples e otimizada, definir ações básicas que Ihes possibilite acompanhar seu ambiente de negócios.

\section{Metodologia do trabalho}

A metodologia utilizada para o desenvolvimento deste trabalho baseia-se em Silva (2000, p.5-6), que a desenvolveu a partir de modelos de vários autores: (PRAHALAD; HAMEL, 1990; McGEE; PRUSAK, 1994; LESCA et al., 1996;
DAVENPORT, 1998; TYSON, 1998), e tem como resultado um diagnóstico sobre o uso e a importância de diversas fontes de informação pela empresa pesquisada, permitindo a proposição do uso de agentes inteligentes.

Para o levantamento de dados, utilizou-se um questionário, desenvolvido tendo como base questões levantadas por Barbosa (1997) e Fidelis (2001) em trabalhos anteriores. O trabalho foi desenvolvido em uma empresa mineira no setor de consultoria e prestação de serviços em gestão da informação e documentação, com mais de 10 anos no mercado.

O modelo proposto por Silva (2000, p.82) tem como instrumento os seguintes modelos:

- Modelo de Alinhamento Estratégico (McGEE; PRUSAK, 1994, p.36)

- Elementos da Definição da Estratégia (McGEE; PRUSAK, 1994, p.54)

- Competências: As Raízes da Competividade (PRAHALAD; HAMEL, 1990, p.81)

- Processo de Vigília Estratégica (LESCA et al., 1996)

- Como estão vinculados os ambientes internos e externos (DAVENPORT, 1998, p.248)

- Inteligência Competitiva e Gestão Estratégica (TYSON, 1998, p.2)

As etapas mais importantes propostas por Silva (2000), para a implantação de atividades de IC são:

1) análise organizacional - a organização precisa responder de maneira formalizada às seguintes perguntas: Quem somos? O que fazemos? Qual é o nosso negócio? A partir deste ponto, formaliza-se a estratégia de atuação de acordo com o modelo de McGee e Prusak (1994, p.54);

$\left.2^{\circ}\right)$ análise: Qual é o ambiente externo? Isto significa a identificação dos elementos externos que podem ter um impacto na organização. Esse é um processo de análise, fundamental para a definição das necessidades de informação externa; 
3) a partir da resposta do segundo passo, ou seja, identificar as necessidades de informação externa, identificam-se as fontes de informação externas - e neste caso, estamos propondo que seja através da Internet;

$\left.4^{\circ}\right)$ monitoramento permanente das fontes; sem o que não há inteligência competitiva.

Com o resultado esperado, propõe-se a atividade de inteligência competitiva utilizando a Internet como ferramenta de busca de informação, com os seguintes objetivos: propor um modelo conceitual para definir as etapas de formulação de um processo de inteligência competitiva; propor um modelo de formalização da estratégia de atuação da organização; propor um modelo de formalização de um mapa indicativo das fontes de informação externas; propor uma base de dados com os endereços das fontes de informação na Internet; propor uma arquitetura de agentes inteligentes vinculados à base de endereços definidos, como mecanismo de monitoramento e alerta.

Sendo assim, este trabalho foi desenvolvido a partir das seguintes etapas:

1ํ Passo) Levantamento da estratégia de atuação: no questionário aplicado procurou-se saber se a empresa pesquisada possuía seu "planejamento estratégico" estruturado para, a partir deste, colocarmos os elementos que atendem à seguinte questão: Quem somos e qual é o nosso negócio?

Ainda de acordo com McGee e Prusak (1994), a estratégia organizacional em um ambiente competitivo, deve considerar três elementos em sua definição: posicionamento/ escopo; estrutura/administração e as competências organizacionais essenciais (core competences).

Para esses autores, enquanto as alternativas de posicionamento e escopo enfatizam a maneira pela qual a empresa é vista por seus clientes, o conceito de competência essencial, assimilado de Prahalad e Hamel (1990), orienta a definição da estratégia quanto aos pontos fortes que uma organização deve possuir de forma a conseguir atender as opções de posicionamento/ escopo consideradas.

O modelo de estrutura/administração baseado na cadeia de valor decompõe a organização em habilidades essenciais, processos e funções necessárias para a criação de seus produtos e serviços. Ele é orientado pelos níveis de capacitação de indivíduos e de pequenos grupos, para desenvolverem e manterem habilidades essenciais e conhecimento. A governância, em si, trata da forma de estruturar e administrar esses indivíduos e grupos de modo a organizar o conhecimento e a habilidade para formar a cadeia de valor completa (McGEE; PRUSAK, 1994).

A estratégia competitiva baseada na informação, é um mapa de informações que responde a perguntas sobre a maneira pela qual a empresa irá operar num mundo onde a informação desempenha um papel fundamental. O valor agregado advém da análise clara da forma de aperfeiçoar o desempenho, em cada nível da organização, com o uso da informação.

As competências essenciais da organização colocam o conhecimento e a informação no centro do elo de ligação entre estratégia e execução. Enfocar as competências essenciais da organização previamente como informação necessária para a definição da estratégia, leva à ampliação deste conceito para uma forma mais prática. Embora a diferença possa parecer sutil, o enfoque em informação e conhecimento afasta a descrição da empresa da que seria a de uma empresa estática, em direção à descrição de um processo dinâmico de inovação e aperfeiçoamento.

O conceito das competências essenciais do modelo McGee e Prusak (1994), considerado neste trabalho, baseou-se na visão da organização desde a perspectiva das competências essenciais, de acordo com o modelo de Prahalad e Hamel (1990, p.81), segundo o qual os pontos 
fortes da organização devem ser cada vez mais fortalecidos.

2ำ Passo) Definição do mapa e grau de relevância das informações: utilizou-se a mesma metodologia de levantamento da estratégia de atuação: entrevista focada no conhecimento do "planejamento estratégico da empresa" e aplicação de questionário, buscando identificar as necessidades de informações externas, a partir da estratégia de atuação formalizada. Os entrevistados foram as sócias proprietárias e equipe de nível gerencial da empresa pesquisada.

3ํㅗ Passo) Definição do mapa de fontes de informação estratégica, disponíveis na Internet: a partir da visão explícita da estratégia de atuação de acordo com os resultados das entrevistas, foi possível configurar as necessidades de informação da empresa pesquisada e, conseqüentemente, configurar o mapa de fontes de informação estratégica, disponíveis na Internet.

4ำ Passo) Definição de uma base de fontes na Internet, com aplicação de agentes inteligentes para o monitoramento: processo não realizado neste trabalho - a definição da base de endereços, com a escolha do software e a própria modelagem, fica a critério de cada organização. O importante é que a base permita a aplicação de agentes no monitoramento de fontes de informação na Internet, o que significa criar uma arquitetura onde os agentes são programados para estarem "alertas" às mudanças ocorridas nos sites determinados em uma base de endereços, além da função "alerta" via e-mail.

\section{Aplicação do modelo e análise dos dados}

\section{Primeiro Passo: Levantamento da estratégia de atuação}

Os elementos da estratégia de atuação adotados aqui, como já dito, seguem o modelo de McGee e Prusak (1994). Esse modelo foi escolhido por apresentar os três elementos que devem ser considerados na estratégia organizacional em um ambiente competitivo. Sendo este dirigido à atuação empresarial, justifica-se a sua utilização.

O processo de inteligência competitiva é dependente da formalização de um mapa informacional externo, definido a partir da estratégia de atuação da organização, a qual deve considerar as suas competências essenciais. Considerando-se isto, o processo de inteligência competitiva pode ser obtido mediante o processo de reformulação de planejamento estratégico efetuado pela empresa considerada neste trabalho (processo que partiu das recentes discussões que possibilitaram a reflexão), e as respostas às perguntas: "quem somos?" e "qual é o nosso “negócio'?”

Portanto, coloca-se a perspectiva das competências essenciais (Figura 3), numa adaptação do modelo de Prahalad e Hamel (1990, p.12), um dos elementos considerados no modelo de McGee e Prusak (1994), e a conseqüente formalização da estratégia de atuação (Anexo 1).

Essa perspectiva concretiza a visualização dos pontos fortes da empresa, apontados na revisão do seu planejamento estratégico, o que possibilita a colocação dos outros elementos da sua estratégia de atuação (Anexo 2).

\section{Segundo Passo: Definição do mapa e grau de relevância das informações}

Com vistas à construção da definição do mapa de informações externas estratégicas, adotamos a mesma metodologia de levantamento da estratégia de atuação: reuniões para discussão tipo "planejamento estratégico" e aplicação de questionário, o que possibilitou-nos a identificação das necessidades de informações externas, a partir da estratégia de atuação formalizada. 
Produtos Finais

(Descritos no Anexo 1)

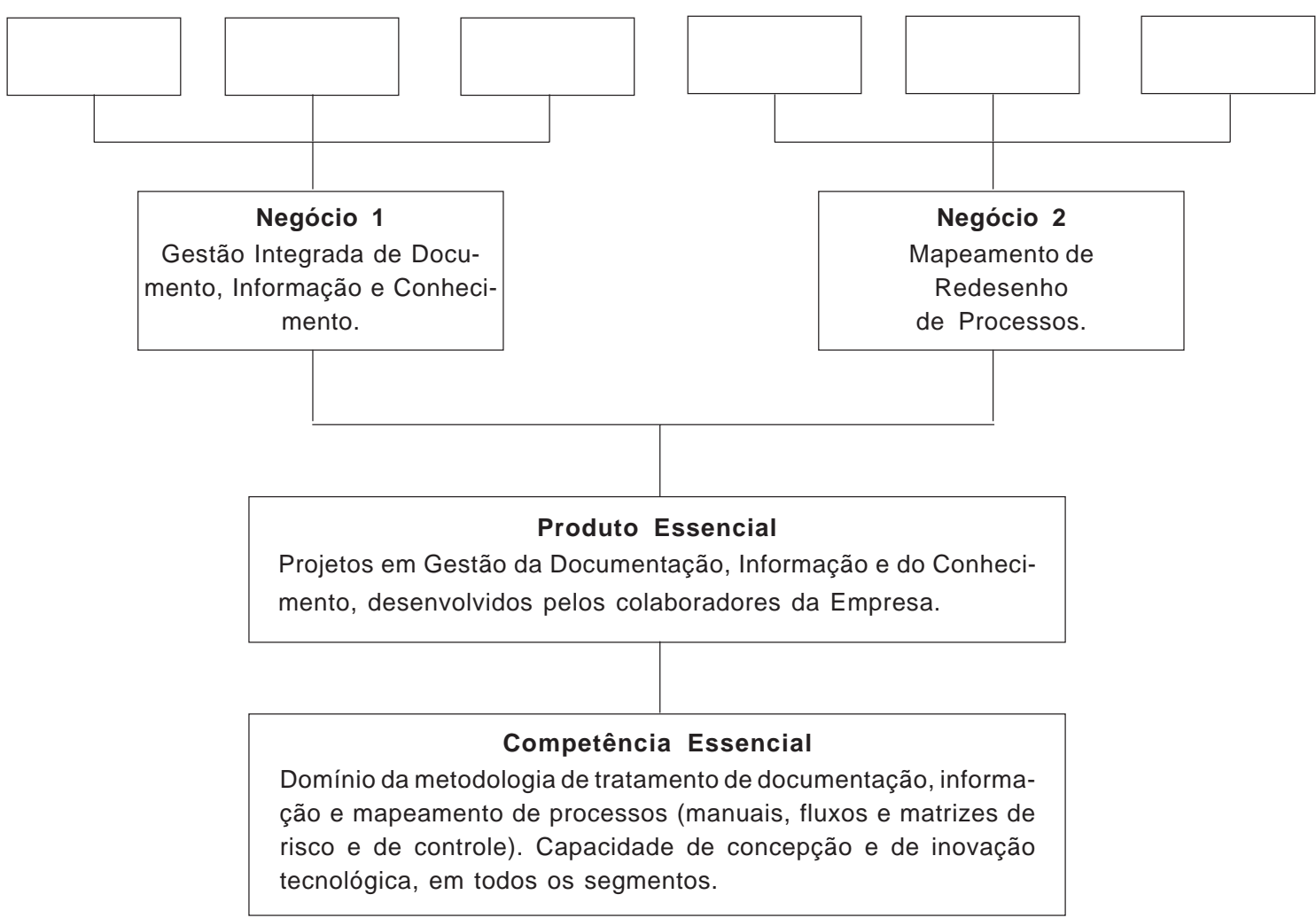

Figura 3. Perspectiva das Competências Essenciais da empresa estudada.

(Adaptado do modelo de Prahalad e Hamel (1990))

Procuramos analisar as necessidades de informação vista sob dois aspectos:

- Quadro 1 - Freqüência de utilização e busca de informações

- Quadro 2 - Grau de relevância da informação

\section{Análise do Quadro 1: freqüência de utilização e busca de informações}

1) Ao analisarmos este quadro no geral, foi-nos possível diagnosticar que a média geral, para a busca de informações, tanto em qualquer fonte, como na Internet, é baixa e, em se tratando de uma empresa focada em documentação, informação e processos, esta é uma lacuna que deve ser preenchida. Além disso, a Internet hoje é fonte riquíssima de informações, que não pode ser desprezada;

2) constatamos que a procura por conhecimento de novas tecnologias, é a única informação coletada que apresenta uma freqüência média em relação às demais, em ambas as situações (informações coletadas em qualquer fonte e coletadas via Internet). Ainda assim, considerando que um dos pontos fortes da empresa é a concentração de produtos diferenciados oferecidos no mercado - metodologia e tecnologia da informação (TI) -, produtos novos para necessidades latentes do mercado, 
devemos sempre estar atentos e criarmos mecanismos de controle diário, pois em se tratando de tecnologia, sua evolução e rotatividade (turn over) no mercado vem sendo muito alta;

3) ter domínio da metodologia de tratamento de documentação, informação e mapeamento de processos (considerado um ponto forte da empresa), não basta, é preciso estar sempre atento e conhecer novos fornecedores e parceiros, que muito agregam ao negócio. Entretanto, o índice de freqüência de busca de informação de fornecedores e parceiros foi pontuado e considerado baixo;

4) medidas do governo normalmente afetam diretamente qualquer negócio, principal-

Quadro 1. Freqüência de utilização e busca de informações.

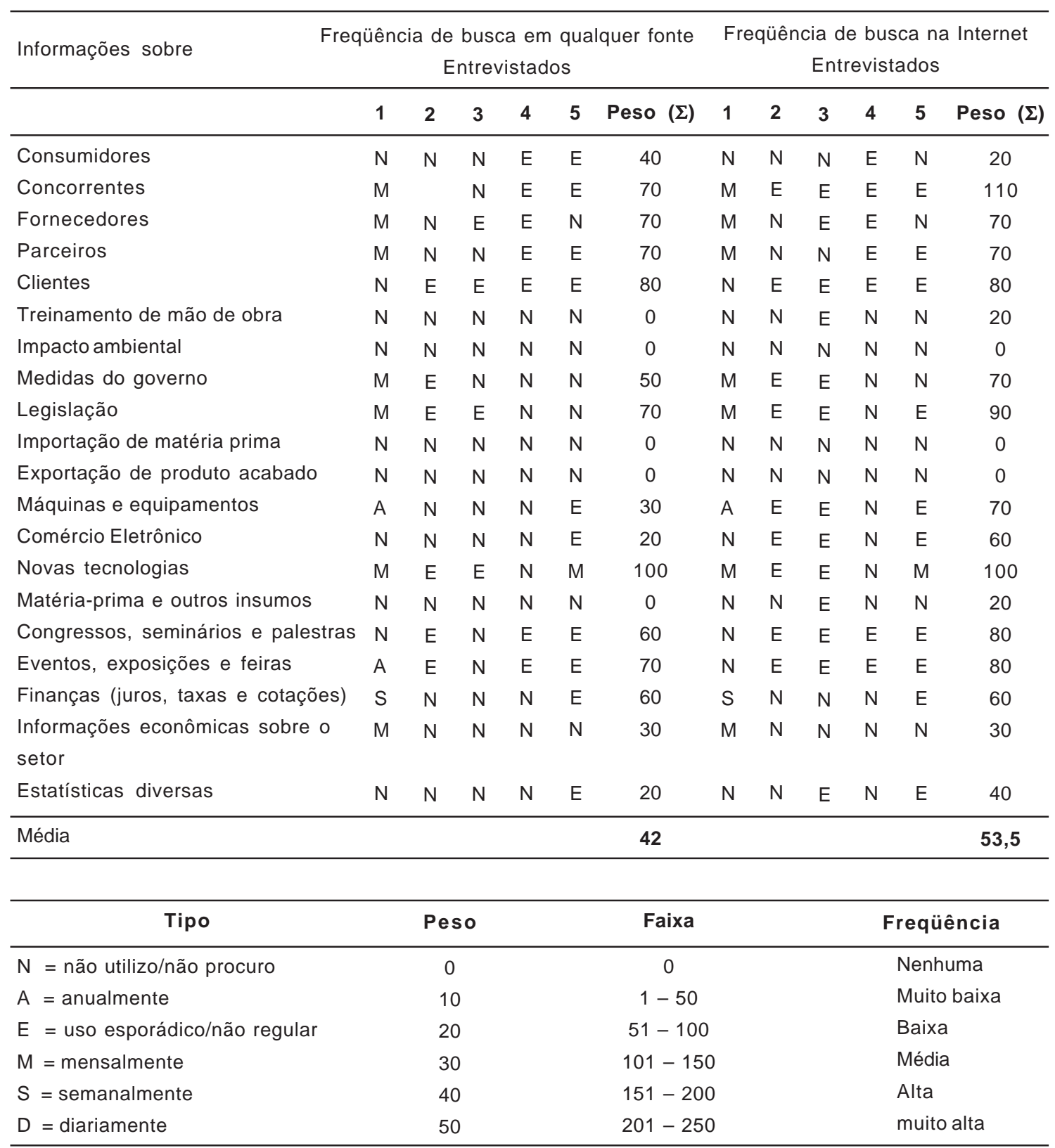


mente no que tange as medidas direcionadas às áreas de TI. Novamente o índice de freqüência de busca por este tipo de informação foi considerado baixo;

5) já o item referente à legislação, apresentou uma estatística média, principalmente na fonte Interna;

6) no que tange à qualificação dos trabalhadores da empresa, a participação em congressos, seminários, palestras, eventos e outros, apresentou-se com uma freqüência de busca média. Porém, foi-nos possível constatar que tal participação não é sistematizada e/ou mesmo geradora de novos conhecimentos e agregação de valor interno à organização. Isso enfatiza um dos pontos fracos apresentados no planejamento - a diversidade de experiência dificulta a definição da atividade principal e dilui as competências. Quais são as competências essenciais e como compartilhá-las? Este é um processo com impacto na construção de uma base sólida de conhecimento e na sua disseminação em prol da organização.

Ao analisarmos os questionários aplicados, à luz do planejamento estratégico da empresa, considerando os negócios da mesma, que são: gestão integrada de documento, informação, conhecimento, mapeamento e redesenho de processos, podemos constatar a partir do quadro, o grau de relevância da informação, conforme segue.

\section{Análise do Quadro 2: Grau de relevância da informação}

1) Em primeira instância, constatamos que, assim como o quadro anterior, a média geral do grau de relevância da informação encontrada nas variadas fontes de informação, é somente média. O maior índice de relevância se concentra nas fontes internas da empresa (colegas de trabalho, colegas do mesmo nível hierárquico; memorandos, circulares), seguidas do meio princi- pal, o meio tecnológico (e-mails e memorandos, circulares via rede interna de computador).

2) O grau de relevância atribuído às fontes (portais corporativos, pesquisas em sites, bibliotecas/centro de informação e serviços externos de informação eletrônica) atingiu a faixa média. Entretanto, considerando tratar-se de uma empresa de consultoria e prestação de serviços em gestão da informação e documentação, tais fontes, sob a ótica do negócio, poderiam ser mais exploradas.

3) Foi-nos possível também verificar que os veículos impressos (papel) vão cedendo lugar à mídia eletrônica, pois os mais altos graus de relevância apontam para os veículos eletrônicos.

Terceiro Passo: Definição dos mapas de fontes de informação estratégicas disponíveis na Internet (Mapas estes que não foram apresen-tados neste artigo)

A partir da visão explícita da estratégia de atuação da empresa pesquisada, foi-nos possível verificar as suas necessidades de informação e, conseqüentemente, configurar os mapas de fontes de informação estratégica disponíveis na Internet, que poderiam atender a essas necessidades e iniciar o trabalho de monitoração.

Quarto Passo: Definição de uma base de fontes na Internet, com aplicação de agentes inteligentes para o monitoramento (processo não realizado neste trabalho)

A definição da base de endereços, com a escolha do software e a sua modelagem, fica a critério de cada organização. O importante é que a base permita a aplicação de agentes no monito-ramento de fontes de informação na Internet, o que significa criar uma arquitetura onde os agentes são programados para estarem "alertas" às mudanças ocorridas nos sites determinados numa base de endereços, além da função "alerta" via e-mail. 
Quadro 2. Grau de relevância da Informação.

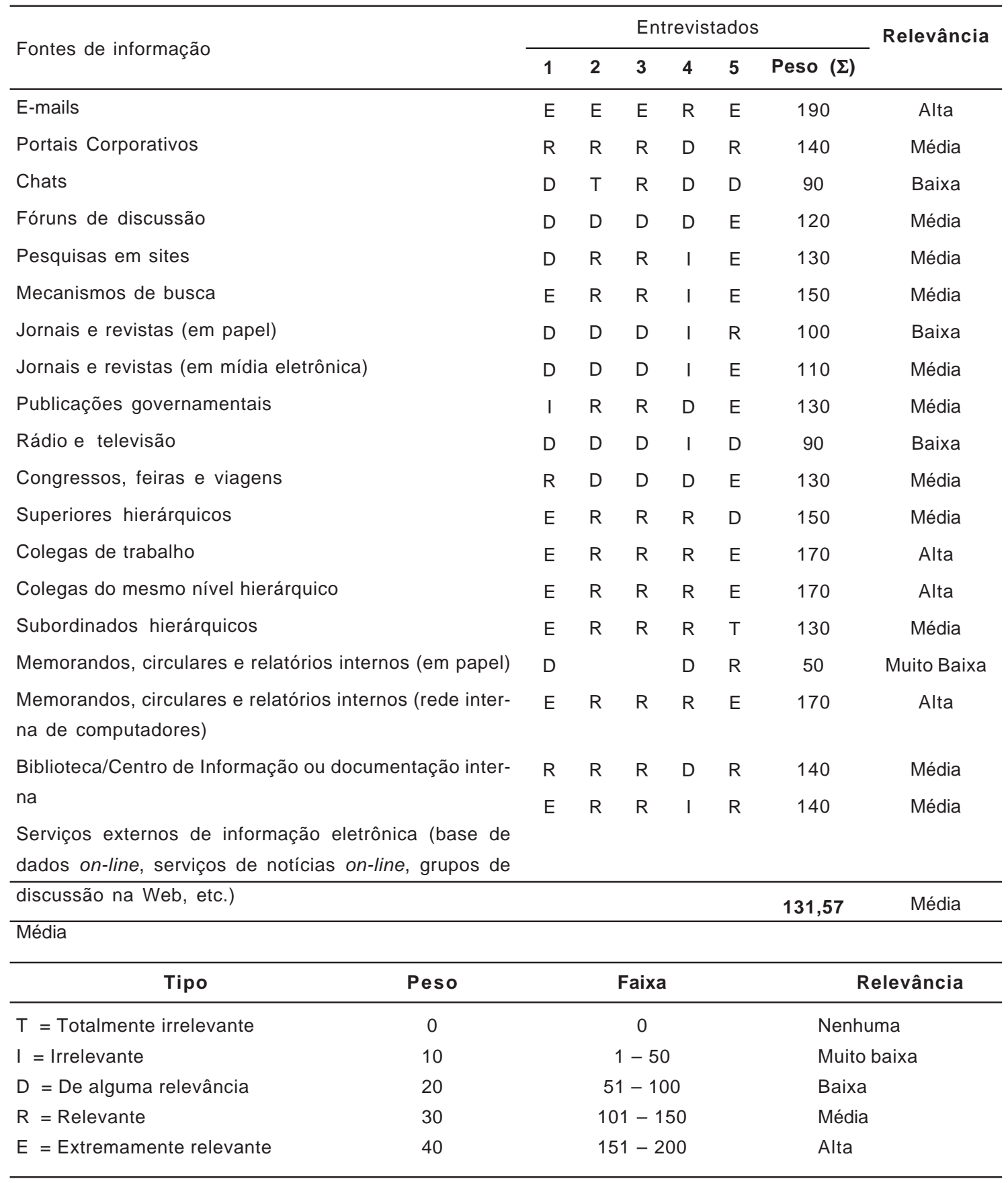

\section{CONSIDERAÇÕ ES FINAIS}

Com base no estudo de caso efetuado numa empresa mineira do setor de consultoria e prestação de serviços em gestão da informação e documentação, este trabalho foi desenvolvido com vistas a responder às seguintes questões: Qual o valor das informações na tomada de decisão estratégica da empresa? Quais as fontes de informação utilizadas? Quais são as informações necessárias para os executivos de nível estratégico da empresa? Quais os recursos 
de monitoramento ambiental, agregação de valor e disseminação de informação que a alta administração possui para dar suporte à tomada de decisão estratégica?

O problema considerado foi: como tornar a Internet uma ferramenta efetiva para a inteligência competitiva? Elaborou-se este trabalho com o objetivo de propor uma atividade de inteligência competitiva utilizando a Internet como ferramenta. Mais especificamente, busca-se formular os seguintes elementos: um modelo conceitual para definir as etapas de formulação de um processo de inteligência competitiva; um modelo de formalização da estratégia de atuação da organização; um modelo de formalização de um mapa indicativo das fontes de informação externas; uma base de dados com os endereços das fontes de informação na Internet; uma arquitetura de agentes inteligentes vinculados à base de endereços definidos, como mecanismos de monitoramento e alerta.

A colocação desse problema partiu do seguinte pressuposto: a Internet serve como ambiente de informação externa e como ferramenta, num processo de inteligência competitiva. Esse pressuposto surge a partir das premissas que compõem um quadro contextual para a consideração da relação: Internet - Inteligência Competitiva. Os pontos principais que podemos destacar são: informação é um recurso estratégico para as organizações; inovação é um fator determinante desse paradigma. Neste sentido, a organização deve estar atenta às mudanças do seu ambiente externo: a inteligência competitiva é uma atividade fundamental para isso; a Internet é um ambiente de informação que pode trazer oportunidades para as organizações. A sua exploração para a busca de informações estratégicas e a utilização das informações aí obtidas, podem constituir vantagem competitiva para as organizações.

\section{a) Quanto à proposta}

A proposta apresentada - processo de inteligência competitiva com base na Internet - considerou: 1) a estratégia de atuação da organiza- ção pesquisada, 2) a definição das informações estratégicas.

Esta foi uma importante questão observada, que aliou os conceitos adotados a modelos teóricos obtidos na fundamentação teórica. A proposta resultou num processo de fácil aplicação, operacional para qualquer organização. Esse processo se baseia nos pontos fundamentais para a atuação das organizações segundo o paradigma atual, como já colocado anteriormente.

\section{Limitações e sugestões}

As limitações deste trabalho levam às seguintes sugestões e prendem-se aos seguintes aspectos:

Quanto ao escopo: Não foi contemplada a análise das informações que vão gerar o conhecimento externo.

- Limitações: o estudo não abrangeu o processo de inteligência competitiva no seu todo.

- Sugestões para estudos que completem o processo: realizar um estudo das técnicas de análise das informações provenientes da Internet, para levar ao conhecimento externo; dentro de uma organização, realizar processosmodelos [?] de como a informação se transforma em conhecimento e leva à tomada de decisão, a partir do processo de inteligência competitiva considerando a Internet; realizar processos-modelos [?] de como introduzir e incorporar o conceito de inteligência competitiva na Internet, de forma a incorporá-lo à cultura organizacional da empresa.

Quanto ao processo proposto, limitações e sugestões:

- Levantamento da estratégia de atuação: sugerimos que este seja feito por meio de reuniões do tipo planejamento estratégico. (Para a elaboração deste trabalho, o mesmo não foi necessário, tendo em vista que o planejamento estratégico da empresa pesquisada tinha sido realizado há 
bem pouco tempo). A sugestão é que, para este tipo de levantamento, envolva-se toda a organização ou representantes de todas as áreas da organização.

- Levantamento para a definição do mapa informacional: sugerimos que a forma seja a mesma utilizada no item anterior. (Para este trabalho, optou-se pela aplicação de questionário às pessoas consideradas estratégicas na organização).

- Rotina de procedimento: este trabalho não contemplou uma rotina de procedimentos, que incluiria o acompanhamento do monitoramento efetuado pelos agentes inteligentes. A sugestão é estabelecer rotinas que possam acompanhar todo o processo. Isso, entretanto, somente será possível, a partir da operacionalização do processo. Notar que este processo deverá ser diferente para cada organização: o acompanhamento das fontes de informação; o acompanhamento dos resultados do monitoramento pelos agentes inteligentes; a disseminação dos resultados aos interessados e o acompanhamento do uso da informação.

- Mapa informacional: este trabalho não apresentou a relação entre as fontes e as áreas

\section{R E F E R Ê N C I A S}

BARBOSA, R.R. Monitoração ambiental: uma visão interdisciplinar. Revista de Administração, v.32, n.4, p.42-53, 1997.

DAVENPORT, T.H. Ecologia da informação: por que só a tecnologia não basta para o sucesso na era da informação. São Paulo: Futura, 1998. 316p.

FIDELIS, J.R.F. A Internet como fonte de informação para inteligência empresarial: um estudo de caso em indústrias de micro, pequeno e médio portes. 2001. Dissertação (Mestrado em Ciência da Informação) - Universidade Federal de Minas Gerais, Belo Horizonte, 2001.

LESCA, H. et al. Como produzir um senso útil para as ações dos dirigentes. READ, v.2, n.2, nov. 1996. Disponível em: <http://read.adm.ufrgs.br/read03/ artigo/freitas1.htm>. Acesso em: 12 jul. 2004.

MCGEE, J.; PRUSAK, L. Gerenciamento estratégico da informação: aumente a competitividade e a de interesse, isto é, quais informações poderiam ser extraídas de cada fonte e a quem elas seriam dirigidas. Sugere-se o estabelecimento dessa relação, o que também, entende-se, somente se efetivará após a operacionalização do processo, sendo necessário fazer uma análise cuidadosa de cada fonte.

- Definição de produtos ou serviços a partir dos resultados de monitoramento: também não foi apresentada essa definição. Isso também somente será possível após a operacionalização do processo.

Essas limitações decorrem de ter sido este trabalho a apresentação de uma proposta conceitual de um processo, proposta que não contemplou a implementação. O processo, apesar de genérico, deverá apresentar resultados de acordo com as características e necessidades de informação de cada organização. O que se observa é a aplicabilidade da metodologia proposta por Silva (2000, p.160), que pode ser útil para as organizações de pequeno e médio porte, as quais geralmente carecem desse tipo de suporte para implementar ações relacionadas à inteligência competitiva.

eficiência de sua empresa utilizando a informação como uma ferramenta estratégica. Rio de Janeiro: Campus, 1994. p.36-54.

PORTER, M. Estratégia competitiva. 9.ed. Rio de Janeiro: Campus, 1991.

PRAHALAD, C.K.; HAMEL, G. The core competence. Harvard Business Review, May/June, p.12-81, 1990.

SILVA, H.P. Inteligência Competitiva na Internet; proposta de um processo. 2000. f.4. Tese (Doutorado em Engenharia de Produção) - Universidade Federal de Santa Catarina, Florianópolis, 2000.

TAKAHASHI, T. (Org.). Sociedade da informação no Brasil: livro verde. Brasília: Ministério da Ciência e Tecnologia, 2000.

TYSON, K.W.M. The complete guide to competitive intelligence. Lisle: Kirk Tyson International, 1998. p.2. 
Anexo 1. Perspectiva das Competências Essenciais da Empresa.

Negócio 1: Gestão Integrada de Documento, Informação e Conhecimento.

Planejamento e implantação de projetos de organização da documentação arquivística, bibliográfica e especial.

Definição do ciclo de vida da informação - Tabela de Temporalidade Documental

Planejamento e implantação de projetos e tecnologia de GED/WORKFLOW

Planejamento e implantação de projetos de organização da documentação eletrônica não estruturada

Terceirização in company de Centros de Documentação e Bibliotecas

Auditoria de processos documentais
Negócio 2: Mapeamento e Redesenho de Processos.

Levantamento e registro de processos organizacionais.

Identificação dos registros documentais associados aos processos

Otimização e automação de processos organizacionais

Planejamento e implantação de projetos e tecnologias que possibilitem a associação de documentos e registros aos processos organizacionais

Elaboração de matrizes de risco/controle

Elaboração de manuais de procedimento

Modelagem de processos e implantação de tecnologia de fluxo de trabalho (workflow)

Definição e implantação de tecnologias de processo de redesenho de negócios (BRP - Business Redesign Process)

Definição e implantação de tecnologias voltadas para o gerenciamento de registros documentais e para a verificação da aderência aos objetivos e metas do negócio (Record Management and Compliance)

Adaptado do modelo de Prahalad e Hamel (1990). 
Anexo 2. Elementos da estratégia de atuação da empresa.

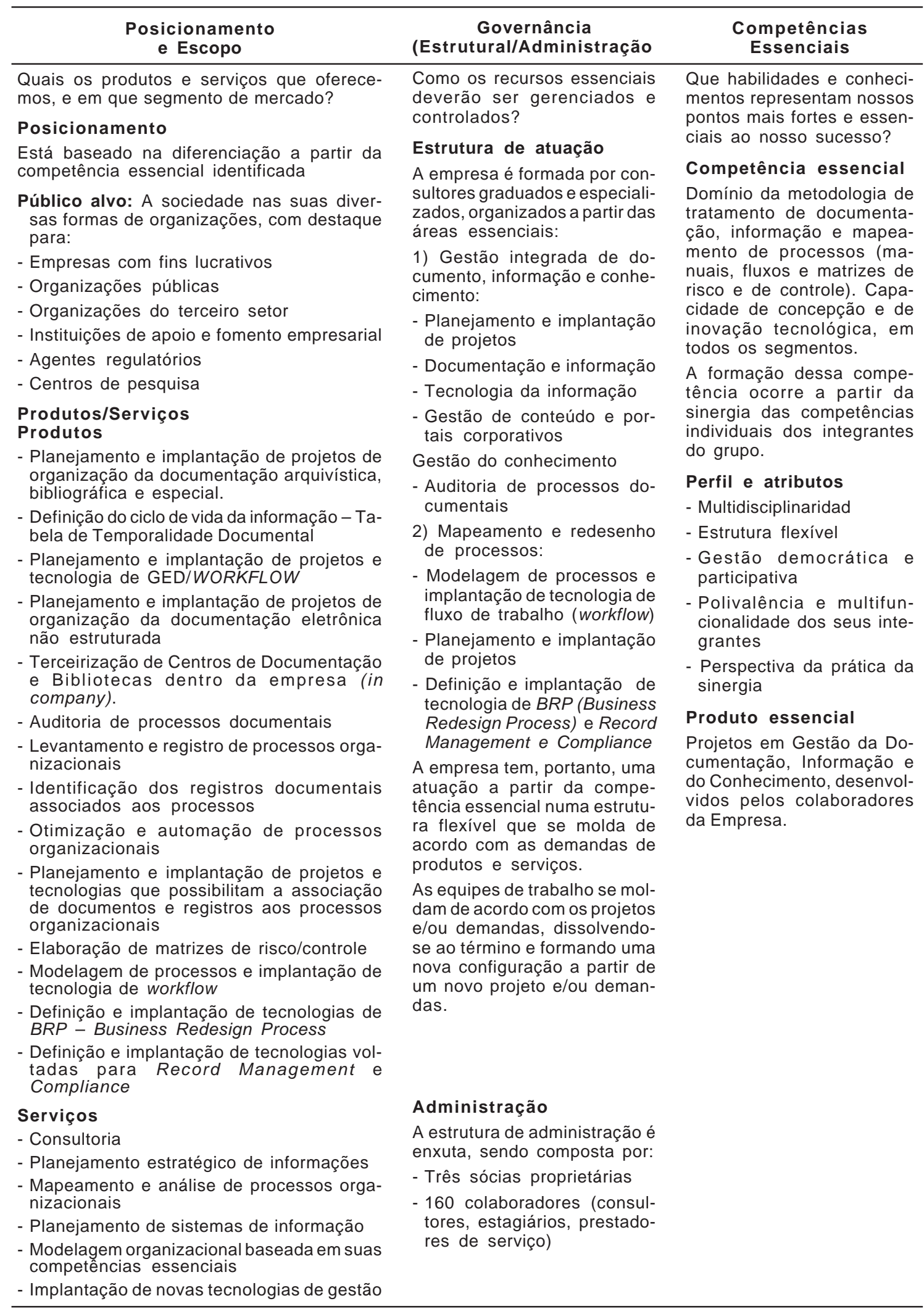


